\title{
The Prevalence of Thyroid Dysfunction among Sudanese Pregnant Women
}

\author{
Amel K. Saeed ${ }^{1}$, Khalid Yassin ${ }^{2}$, Elmahdi M A. Elmahdi ${ }^{3}$, Druce Maralyn ${ }^{4}$, AbdelAziem A. Ali ${ }^{\text {* }}$ \\ ${ }^{1}$ Faculty of Medicine, Department of Medicine, Alneelain University, Sudan \\ ${ }^{2}$ Faculty of Medicine, Department of Obstetrics and Gynecology, Alneelain University, Sudan \\ ${ }^{3}$ Faculty of Medicine, Department of Medicine, Khartoum University, Sudan \\ ${ }^{4}$ Bart's and the London school of Medicine, Department of Endocrinolgy, UK \\ ${ }^{5}$ Faculty of Medicine, Department of Obstetrics and Gynecology, Kassala University, Sudan
}

Received: April 21, 2015; Accepted: May 25, 2015; Published: June 15, 2015

*Corresponding author: Abdel Aziem A. Ali, P.O. Box 496, Department of Obstetrics and Gynecology, Faculty of Medicine, Kassala University, Kassala, Sudan, Tel: +249912351175; Fax:+249411823501; E-mail: abuzianab73@yahoo.com

\begin{abstract}
Background: Thyroid dysfunctions are most prevalent in women during their most fertile years (15-35), and for a long time thyroid dysfunctions have been linked with poor reproductive health and pregnancy outcomes.

Methods: All pregnant ladies- aged 15 to 45 years- who attended ante-natal clinics in Al Amal National hospital and Ribat University hospital, Khartoum, Sudan during the period of May-July 2014 were included to investigate the prevalence and risk of thyroid dysfunctions, to determine trimester-specific reference ranges for free Tri-Iodothyronine (FT3), Free Thyroxin (FT4) and Thyrotrophin (TSH) among healthy pregnant Sudanese women. Chi square test and logistic regression analyses were performed. Confidence intervals of 95\% were calculated and $P<0.05$ was considered significant.
\end{abstract}

Findings: During the study period a total of 500 pregnant women were included, their mean age, duration of marriage and parity was $(26.43 \pm 5.1)$ year, $(5.378 \pm 4.2)$ year and $(2.8 \pm 0.2)$ respectively. The prevalence of thyroid dysfunctions among the respondents was $9.4 \%$ $(47 / 500)$. On further analysis and with regard to thyroid dysfunctions $3.4 \%$ of the women were found having hyperthyroidism, $2.8 \%$ was hypothyroid, $1.8 \%$ had simple goitre and $1.4 \%$ were diagnosed and treated as thyroiditis. Additionally, we found that 3\% (15/500) of our studied group have thyroid disorders which were discovered for the first time after testing their thyroid functions during this study while $6.4 \%(32 / 500)$ were diagnosed prior to our study. The average ranges of TSH was $(0.08-4.77 \mathrm{mIU} / \mathrm{L}), \mathrm{T} 3(0.30-5.42 \mathrm{nmol} / \mathrm{L})$ and T4 $(0.16-4.70 \mathrm{pg} \mathrm{ml})$ and there was slight fluctuation of the mean values of thyroid hormones according to trimester in Euthyroid pregnant women. Family history of autoimmune diseases (AID) (OR $=11$; $\mathrm{CI}=$, 1.1-66.5; $P=0.033)$ and rural residence $(\mathrm{OR}=13.8 ; \mathrm{CI}=3.5-56$; $P=0.000$ ) were significantly associated with thyroid dysfunctions among our respondents.

Conclusions: We recommend investigation for thyroid function test during pregnancy and in preconception clinics.

Keywords: Prevalence; Thyroid disease; Pregnancy; Sudan

\section{Introduction}

The thyroid gland plays a vital role in body metabolism, through the production of thyroid hormones, which are known to have important actions in controlling many of the human reproductive functions [1]. Thyroid dysfunctions are most prevalent in women during their most fertile years (15 - 35), and for a long time thyroid dysfunctions have been linked with poor reproductive health and pregnancy outcomes [2]. When a female with an uncorrected thyroid dysfunction becomes pregnant, this may have terrible adverse effects on fetal and maternal wellbeing, particularly the neuro-intellectual development of the fetus [3]. Thyroid gland diseases vary according to the environment, diet, heredity and social background [4]. Iodine deficiency is one of the commonest environmental factors responsible for thyroid diseases, More than one billion persons are at risk of iodine deficiency worldwide and 200 million have goitre [5]. In Sudan, iodine deficiency and endemic goitre and variable thyroid dysfunctions are persistent health problems, with the prevalence of goitre reaching up to $22 \%$ in some areas, (with a range of $13 \%$ to $87 \%$ ) [5]. Although the salt iodination program was introduced in Sudan as early as the 1970s the problem is still there, and it is expected to affect mainly neonates, children and young females. However, only a few studies have been conducted on this issue in Sudan, most of them many years ago [5]. The investigation and management of thyroid dysfunctions are not considered in routine screening protocols of pregnant women, or of those planning to get pregnant, even though missing the diagnosis and the delay in managing the thyroid dysfunctions has been proved to have a deleterious effect on the wellbeing of mother and offspring. Thus this study was designed and directed to investigate the prevalence of thyroid dysfunctions in pregnancy and to provide the health planner with fundamental data necessary for appropriate intervention.

\section{Material and Methods}

This was a cross sectional hospital based study designed to investigate the prevalence and spectrum of thyroid dysfunctions 
among pregnant Sudanese females aged $15-45$ years, to determine the common types of thyroid dysfunctions among pregnant ladies and to determine trimester-specific reference ranges for free Tri-Iodothyronine (FT3), Free Thyroxine (FT4) and Thyrotropin (TSH) among healthy pregnant Sudanese women. All pregnant ladies- aged 15 to 45 years- who attended antenatal clinics in Al Amal National hospital and Ribat University hospital, Khartoum, capital city of Sudan during the period of May-July 2014 and who agreed to participate in the study were included. According to these criteria the total number of patients attended the antenatal clinics during the period of the study were 518, but 12 declined to participate in the study, 6 patients were excluded due to incomplete data and 500 were the final number of participants. After we obtained signed informed consent the data has been collected by direct interview with patients, by four trained data collectors, using a detailed structured questionnaire, covering socio-demographic information (age, residence, education, and occupation), history of thyroid disease and past medical history (diabetes mellitus, auto-immune disease, hypertension...etc.). Also the questionnaire included the obstetric (parity, history of miscarriage, stillbirth delivery, preterm birth...etc.) and gynaecological (delay of conception, irregular menstrual period) data. This was followed by, systemic clinical examination and examination of the thyroid gland. $5 \mathrm{ml}$ of venous blood sample were collected from each participant to evaluate the thyroid function; serum was separated immediately by a fine centrifugation machine and sent for thyroid function test. TSH, free T3 and free T4 were quantitatively determined using Microparticle Enzyme Immunoassay (MEIA). We compared the obstetric and gynaecological data and socio-demographic characteristics between the women who were suffering from thyroid dysfunction and those who were euthyroid. All participants were under multidisciplinary care and were treated according to their diagnosis.

The different variables were compared between the women with thyroid dysfunction and euthyroid women. Proportions were compared between the two groups of the study using chi-square test. Univariate and multivariate analyses were performed. Thyroid dysfunction was the dependent variable; socio-demographic characteristics, obstetric and gynaecological data were independent variables. Confidence intervals of $95 \%$ were calculated and $P<0.05$ was considered significant. In case of discrepancy between the results of the univariate and the results of multivariate analyses, the later was taken as final.

\section{Results}

\section{Baseline Characteristics}

During the study period a total of 500 pregnant women were included, their mean age, duration of marriage and parity was $(26.43 \pm 5.1)$ year, $(5.378 \pm 4.2)$ year and $(2.8 \pm 0.2)$ respectively. The vast majority had completed university education $(72.4 \%)$, most of the women were housewives (85.4\%) and the largest group was coming from the urban regions of Sudan (55\%). Significant medical history and co-morbidity was found in 10 patients as follow: $6(1.2 \%)$ patients with diabetes mellitus and 4 $(0.8 \%)$ patients with hypertension. Thirteen women gave family history of auto-immune disease.

\section{Thyroid function among the investigated women}

From the study, we found that the prevalence of thyroid dysfunctions among Sudanese pregnant females evaluated for thyroid dysfunction was $9.4 \%$ (47/500). On further analysis and with regard to thyroid dysfunctions $3.4 \%$ of the women were found having hyperthyroidism, $2.8 \%$ having hypothyroid, $1.8 \%$ having simple goitre and $1.4 \%$ were diagnosed and treated as thyroiditis. Additionally, we found that 3\% (15/500) of our studied group have thyroid disorders which were discovered for the first time after testing their thyroid functions during this study while $6.4 \%(32 / 500)$ were diagnosed prior to our study. Of the newly diagnosed group $80 \%(12 / 15), 13.3 \%(2 / 15)$ and $6.7 \%(1 / 15)$ has hyperthyroid, hypothyroid and simple goitre respectively. Most of the respondents who were suffered from thyroid dysfunction prior to this study had not had their thyroid functions rechecked or corrected prior to conception (21/32, $65.6 \%$ ), and many were not on regular follow up or treatment at the time of the study, and were still having active or uncontrolled disease $(19 / 32,59.4 \%)$. As one of our objectives was to try to estimate the mean average of thyroid hormone levels among healthy pregnant Sudanese females who have normal thyroid function (according to the international values), we found the average ranges of TSH was (0.08-4.77 mIU/L), T3 (0.30-5.42 $\mathrm{nmol} / \mathrm{L}$ ) and T4 (0.16 - $4.70 \mathrm{pg} \mathrm{ml}$ ) Table 1. Also there was slight fluctuation of the mean values of thyroid hormones according to trimester in Euthyroid pregnant women as follow: T4 increased by $0.2267 \mathrm{pg} \mathrm{ml}$ in the second trimester and by $0.0913 \mathrm{pg} \mathrm{ml}$ in the third trimester while T3 dropped by $0.7814 \mathrm{nmol} / \mathrm{L}$ in the second trimester and by $0.8867 \mathrm{nmol} / \mathrm{L}$ in the third trimester, again TSH slightly dropped by $0.298 \mathrm{mIU} / \mathrm{L}$ and $0.2818 \mathrm{mIU} / \mathrm{L}$ in the second and third trimesters respectively, Figure 1.

\section{Obstetric and gynaecological data associated with thyroid dysfunction}

Among the patients with thyroid dysfunction (47 women) $17(36.1 \%)$ gave history of miscarriage, $3(6.4 \%), 1(2.1 \%), 1$ (2.1\%), $6(12.6 \%)$ and $4(8.5 \%)$ gave history of preterm birth delivery, stillbirth delivery, delivery of mentally retarded baby, delay of conception and irregular menstrual cycle respectively. In comparison with euthyroid women the study revealed that the history of miscarriage was significantly associated with thyroid dysfunction (36.1\% Vs $18.3 \%, P=0.006)$, however our study failed to demonstrate any statistical association between, preterm birth delivery, stillbirth delivery, history of delivering mentally retarded baby, history of delay to conceive (described as inability to conceive for one year or more of unprotected sexual intercourse) and history of irregular menstrual cycle and thyroid disorders Table 2.

\section{Risk factors for thyroid dysfunction}

On trying to point out the possible risk factors for thyroid 
Table 1: Thyroid hormone levels among Sudanese pregnant females with normal thyroid function - Sudan- 2014.

\begin{tabular}{|c|c|c|c|c|c|}
\hline & & Test & Mean \pm SD & Minimum & Maximum \\
\hline \multirow{3}{*}{$\begin{array}{l}\text { Level of thyroid hormones in all Euthyroid } \\
\text { females }\end{array}$} & & TSH & $1.70 \pm .89$ & 0.08 & 4.77 \\
\hline & & T3 & $3.41 \pm .89$ & 0.30 & 5.42 \\
\hline & & $\mathrm{T} 4$ & $0.83 \pm 0.61$ & 0.16 & 4.70 \\
\hline \multirow{8}{*}{$\begin{array}{l}\text { Level of thyroid hormones in Euthyroid females } \\
\text { per trimester }\end{array}$} & \multirow{3}{*}{$1^{\text {st }}$} & TSH & $1.793 \pm 0.89$ & 0.30 & 4.24 \\
\hline & & T3 & $4.4469 \pm 0.99$ & 0.30 & 4.94 \\
\hline & & $\mathrm{T} 4$ & $0.803 \pm 0.8$ & 0.44 & 4.70 \\
\hline & \multirow{3}{*}{$2^{\text {nd }}$} & TSH & $1.4413 \pm 1.0$ & 0.06 & 4.77 \\
\hline & & T3 & $3.6653 \pm 0.9$ & 0.50 & 5.00 \\
\hline & & $\mathrm{T} 4$ & $1.03 \pm .54$ & 0.16 & 4.00 \\
\hline & \multirow{2}{*}{$3^{\text {rd }}$} & TSH & $1.4575 \pm 1.03$ & 0.06 & 9.34 \\
\hline & & T3 & $3.56 \pm 0.89$ & 0.80 & 5.42 \\
\hline
\end{tabular}

\section{thyroid hormone fluctuation according to trimester}

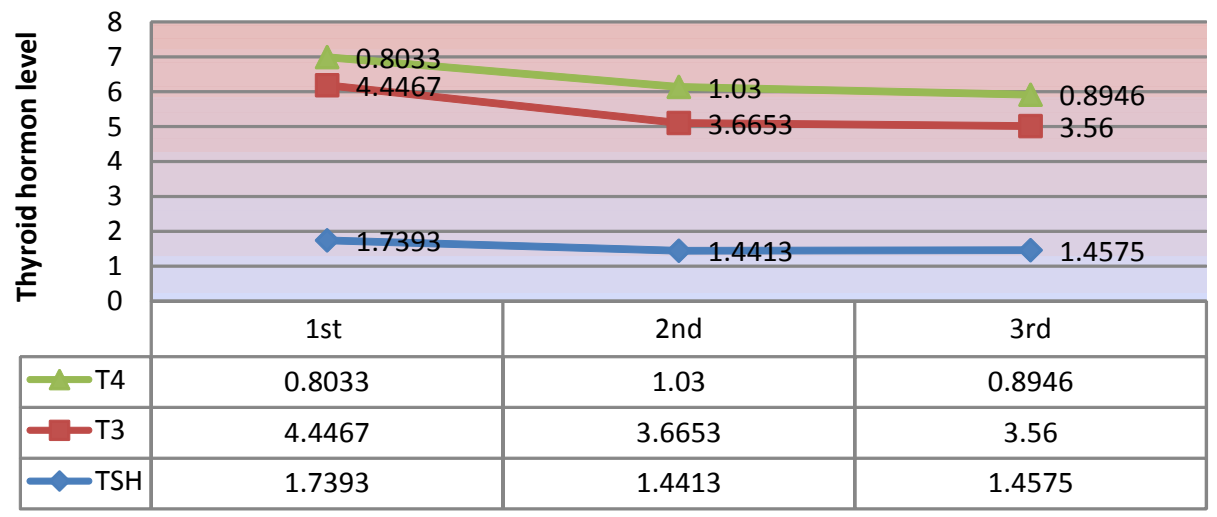

Figure 1: Shows the fluctuation of the mean values of thyroid hormones according to trimester in Euthyroid pregnant Sudanese females- Sudan 2014.

Table 2: Comparison showing the obstetric outcome and gynecological data between pregnant women with thyroid dysfunctions and euthroid women, Sudan, 2014 using chi-square test.

\begin{tabular}{|l|l|l|l|}
\hline Variable & $\begin{array}{l}\text { With thyroid } \\
\text { dysfunction } \\
\mathbf{( 4 7 )}\end{array}$ & $\begin{array}{l}\text { Euthroid } \\
\text { (N=453) }\end{array}$ & $\boldsymbol{P}$ \\
\hline Miscarriage & $17(36.1 \%)$ & $83(18.3 \%)$ & 0.006 \\
\hline Preterm birth & $3(6.4 \%)$ & $28(6.1 \%)$ & 0.723 \\
\hline Stillbirth delivery & $1(2.1 \%)$ & $13(2.8 \%)$ & 0.272 \\
\hline Mentally retarded baby & $1(2.1 \%)$ & $1(0.2 \%)$ & 0.108 \\
\hline Delay of conception & $6(12.6 \%)$ & $42(9.2 \%)$ & 0.140 \\
\hline Irregular cycle & $4(8.5 \%)$ & $5(1.1 \%)$ & 0.001 \\
\hline
\end{tabular}

dysfunctions among our patients, family history of autoimmune diseases (AID) $(\mathrm{OR}=11 ; \mathrm{CI}=, 1.1-66.5 ; P=0.033)$ and rural residence $(\mathrm{OR}=13.8 ; \mathrm{CI}=3.5-56 ; P=0.000)$ were significantly associated with thyroid dysfunctions among our respondents, Table 3.

\section{Discussion}

In this study we aimed to detect the prevalence of thyroid dysfunctions during pregnancy, also, we tried to find out the mean values and range of thyroid hormones in general and also trimester specific levels in euthyroid healthy pregnant females. The hypothyroidism which this study describes $(2.8 \%)$ is in line with what was observed in Gaza population (2.2\%) and similar to the prevalence rate of hypothyroidism among European (2.2\%) and American pregnant women (2.5\%) [6]. On the other hand, the prevalence of hyperthyroidism in our study was very high (3.4\%) as compared with other studies (Gaza $1.0 \%$ ) and $(1.3 \%)$ in Tunisia, but it is similar to review done by Daniel (3-4\% in all pregnant women) $[7,8]$. It might not be valid to compare our results with results in the industrialized countries because the magnitude and effect of iodine deficiency and other environmental or genetic factors on thyroid function of pregnant Sudanese females has never been studied seriously [5].

Although we found that $68.1 \%$ of patients with thyroid disease 


\begin{tabular}{|l|l|l|l|l|l|l|l|}
\hline Table 3: Risk factors for thyroid dysfunction among Sudanese pregnant women, 2014, using univariate and multivariate analyses. \\
\hline Variable & Univariate analyses & \multicolumn{2}{l|}{ Multivariate analyses } \\
\hline & OR & $\mathbf{9 5 \%}$ CI & P-value & OR & $\mathbf{9 5 \%}$ CI & P-value \\
\hline Age $\geq 35$ & 1.0 & $1.0-1.1$ & 0.043 & 1.1 & $1.0-1.1$ & 0.034 \\
\hline Parity $\geq 5$ & 1.1 & $0.9-1.2$ & 0.221 & 0.9 & $0.6-1.2$ & 0.771 \\
\hline Rural residence & 7.2 & $2.8-22$ & 0.001 & 13.8 & $3.5-56$ & 0.000 \\
\hline Comorbidity, yes & 1.1 & $0.4-2.8$ & 0.758 & 1.7 & $0.4-6.4$ & 0.403 \\
\hline Family history of AID & 7.5 & $1.6-36.1$ & 0.010 & 11.0 & $1.1-66.5$ & 0.033 \\
\hline
\end{tabular}

had been diagnosed previously, most of them had not had their thyroid functions rechecked or corrected prior to conception, and many were not on regular follow up or treatment at the time of the study, and were still having active or uncontrolled disease. It is highly recommended that all females with pre-existing thyroid diseases should have their thyroid function rechecked and normalized prior to conception, and thyroid functions monitored throughout pregnancy, especially during the first 12 gestational weeks when the maternal thyroid is solely responsible for delivering thyroid hormone to the growing fetus, which is crucial for its normal brain development [9].

In this study, we found that $\mathrm{T} 3$ dropped by $0.7814 \mathrm{nmol}$ /L in the second trimester and by $0.8867 \mathrm{nmol} / \mathrm{L}$ in the third trimester. This is similar to the results found in a study done in China where they found the highest level of FT3 was during the first trimester [10], and in concordance with some other studies in this field such as that done by Kurioka and his colleagues, who reported significantly reduced levels of free T3 and free T4 during pregnancy [11]. The mean T4 levels were estimated at 0.8033 in the first trimester, increased to 1.03 in the second trimester and to 0.8946 in the third trimester in the euthyroid group. Mean TSH levels were 1.793 microlU/ $\mathrm{ml}$ in the first trimester, 1.4413 $\mathrm{microlU} / \mathrm{ml}$ in the second trimester and $1.4575 \mathrm{microlU} / \mathrm{ml}$ in the third trimester of pregnancy. Although slightly higher during first trimester, these levels are still within the recommended levels of the American Thyroid Association Task force on Thyroid Disease during Pregnancy 2011 [12]. The reference range for TSH is lower throughout pregnancy, in that both the lower normal limit and the upper normal limit of serum TSH are decreased by about 0.1-0.2 $\mathrm{mIU} / \mathrm{L}$, and they recommended that if trimester-specific reference ranges for TSH are not available in the laboratory, the reference ranges recommended are: first trimester, 0.1$2.5 \mathrm{mIU} / \mathrm{L}$; second trimester, $0.2-3.0 \mathrm{mIU} / \mathrm{L}$; third trimester, 0.3-3.0 mIU/L [12]. During normal pregnancy, significant but reversible changes in thyroid function might occur as a result of the normal physiological and hormonal changes, such as the influence of the Human Chorionic Gonadotropin (HCG) as a weak stimulus of thyroid hormones production resulting in subclinical hyperthyroidism. Also, the high estrogen level increases serum thyroid hormone binding proteins, with a consequent increase of the total level of thyroid hormones. These possible changes should be considered when interpreting the thyroid function test during pregnancy [9]. In agreement with our results Stricker et al. (Switzerland) and Soldin et al. (USA) observed similar fluctuation in the trimester specific levels of thyroid hormones $[13,14]$.
Although there is still no strong evidence concerning the effect of the thyroid disease on pregnancy there are clear data confirmed that with thyroid dysfunction there is increase risk of miscarriage, premature delivery, preeclampsia, low birth weight [15-18]. Our study demonstrated significant association between thyroid dysfunction and history of miscarriage. This fact might be changed if the patients were adherent to the follow up and preconception management. Interestingly thirteen women with thyroid dysfunction gave family history of auto-immune disease and there were 4 cases claimed that their menstrual period was irregular. The immune system may produce antibodies against the ovarian tissue, harming the egg-containing follicles and damaging the egg [19]. What triggers the immune response is unclear, but may be explained by being a multiple endocrinological dysfunction. Among the different socio-demographic and risk factors rural residence was found significantly associated with thyroid disorders among the investigated pregnant women. This might be attributed to change in diet and iodine intake; however more research is needed to conclude an evidence for this factor.

\section{Limitations}

Limitation of this study is partly due to the small size sample and being confined to only two hospitals which underestimate the actual burden the problem. Also the study didn't consider the iodine as an important element in thyroid function test.

\section{Conclusions}

Thyroid dysfunction is highly prevalent among Sudanese pregnant women. There is slight fluctuation of thyroid hormones during pregnancy in euthyroid women and thyroid dysfunction is affected by rural residence and history of auto-immune disorder. We recommend more researches in this field and advice routine investigation for thyroid function test during pregnancy and in preconception clinics.

\section{Acknowledgement}

We sincerely thank all women who participated in this study.

\section{Ethical approval}

The study approved and received ethical clearance from the Research Board at Alneelain University, Sudan.

\section{References}

1. Okosieme OE, Marx H, Lazarus JH. Medical management of thyroid dysfunction in pregnancy and the postpartum. Expert Opin Pharmacother. 2008; 9(13): 2281-93. 
2. Onyebuchi EO, John HL. Thyroid dysfunction in pregnancy: optimizing fetal and maternal outcomes. Expert Rev Endocrinol Metab. 2010; 5(4): 521-529.

3. Brian MC, Kenneth JL. Thyroid Disease in Pregnancy. Obstetrics \& Gynecology. 2006; 108: 1283-1292.

4. American Thyroid Association. Thyroid Disease and Pregnancy. 2012.

5. Medani AM, Elnour AA, Saeed AM. Endemic goiter in the Sudan despite long-standing program for the control of iodine deficiency disorders. Bull World Health Organ. 2011; 89(2): 121-126.

6. Radi RA. Assessment of Thyroid Function in Pregnant Women From Rimal Health Center, Gaza City. 2010.

7. Feki M, Omar S, Menif O, Tanfous NB, Slimane H, Zouari F, et al Thyroid disorders in pregnancy: Frequency and association with selected diseases and obstetrical complications in Tunisian women. Clin Biochem. 2008; 41(12): 927-31.

8. Glinoer D. Thyroid Hyperfunction during Pregnancy. Thyroid. 1998; 8(9): 859-864.

9. Soldin OP, Tractenberg RE, Hollowell JG, Jonklaas J, Janicic N, Soldin SJ Trimester-specific changes in maternal thyroid hormone, thyrotropin, and thyroglobulin concentrations during gestation: trends and associations across trimesters in iodine sufficiency. Thyroid 2004; 14(12): 1084-1090.

10. Pasupathi P, Chandrasekar V, Kumar S. Thyroid Hormone Changes: Pregnant and Non-Pregnant Women: A Case-Control Study. Thyroid Science. 2009; 4(3): 1-5.

11. Kurioka H, Takahashi K, Miyazaki K. Maternal thyroid function during pregnancy and puerperal period. Endocr J. 2005; 52(5): 587-91.

12.Stagnaro-Green A, Abalovich M, Alexander E, Azizi F, Mestman J,
Negro R, et al. Guidelines of the American Thyroid Association for the diagnosis and management of thyroid disease during pregnancy and postpartum. Thyroid. 2011; 21(10):1081-125.

13. Stricker R, Echenard M, Eberhart R, Chevailler MC, Perez V, Quinn FA, et al. Evaluation of maternal thyroid function during pregnancy: the importance of using gestational age-specific reference intervals. Eur J Endocrinol. 2007; 157(4): 509-514.

14. Soldin OP, Soldin D, Sastoque M. Gestation-specific thyroxine and thyroid stimulating hormone levels in the United States and worldwide. Ther Drug Monit. 2007; 29(5): 553-559.

15. Benhadi N, Wiersinga WM, Reitsma JB, Vrijkotte TG, Bonsel GJ. Higher maternal TSH levels in pregnancy are associated with increased risk for miscarriage, fetal or neonatal death. Eur J Endocrinol. 2009; 160(6): 985-991.

16. Antolic B, Gersak K, Verdenik I, Novak-Antolic Z. Adverse effects of thyroid dysfunction on pregnancy and pregnancy outcome: epidemiologic study in Slovenia. J Matern Fetal Neonatal Med. 2006; 19(10): 651-654.

17. Allan WC, Haddow JE, Palomaki GE, Williams JR, Mitchell ML, Hermos RJ, et al. Maternal thyroid deficiency and pregnancy complications: implications for population screening. J Med Screen. 2000; 7(3): 127130.

18. Stagnaro-Green A. Maternal thyroid disease and preterm delivery. J Clin Endocrinol Metab. 2009; 94(1): 21-25.

19. Negro R, Mangieri T, Coppola L, Presicce G, Casavola EC, Gismondi R, et al. Levothyroxine treatment in thyroid peroxidase antibody-positive women undergoing assisted reproduction technologies: a prospective study. Hum. Reprod. 2005; 20(6): 1529-1533. 